\title{
José Marques de Melo e a escola latino-americana de comunicação: obra, pensamento e história
}

\author{
José Marques de Melo and Latin American school of communication: \\ work, thought and history \\ Livia Marques Ferrari de Figueiredo ${ }^{1}$ \\ (liviamarquesferrari@hotmail.com) \\ Simone Antoniaci Tuzzo ${ }^{2}$ \\ (simonetuzzo@hotmail.com) \\ http://dx.doi.org/10.5216/cei.v16i1.25569
}

\begin{abstract}
Resumo
Este estudo propõe uma compreensão referente à vida e obra de um dos teóricos precursores da Escola Latino Americana de Comunicação, José Marques de Melo. O trabalho ainda aponta as principais ideias e conceitos desenvolvidos pelo autor, revisitando algumas de suas obras. Por meio de análise bibliográfica, tornou-se possível traçar uma visão panorâmica do aprimoramento das pesquisas em comunicação em regiões latinas da América, bem como do surgimento e estabelecimento de uma Escola Latino Americana de Comunicação. A relevância de Marques de Melo para este pensamento é explanada neste estudo, além de sua contribuição na defesa do Jornalismo como campo científico e de conhecimento independente. Seu valioso enfoque, alusivo à importância do empirismo para o entendimento dos fenômenos comunicacionais e para a construção de conhecimento científico na área, é elucidado no trabalho.
\end{abstract}

Palavras-chave: Empirismo. Escola Latino-Americana. Jornalismo. Comunicação.

\begin{abstract}
This study proposes an understanding regarding the life and work of one of the theoretical precursors of Latin American School of Communication, José Marques de Melo . The paper also points out the main ideas and concepts developed by the author, revisiting some of his works. Through literature review, it became possible to draw an overview of research in the improvement of communications in regions of Latin America as well as the emergence and establishment of a Latin American School of Communication. The relevance of Marques de Melo for this thought is explained in this study, in addition to its contribution to the defense of journalism as a scientific field and independent knowledge. Your valuable approach, illustrating the importance of empiricism to the understanding of communication phenomena and the construction of scientific knowledge in the area, is elucidated in the work.
\end{abstract}

Keywords: Empiricism. Latin American school. Journalism. Communication.

\footnotetext{
${ }^{1}$ Professora, Mestre e Graduada em Comunicação Social pela Faculdade de Comunicação e Biblioteconomia - FACOMB, da Universidade Federal de Goiás - UFG. Pesquisadora dos Grupos de Pesquisa: Mídia, Imagem e Cidadania; Bases Epistemológicas para uma leitura crítica da mídia da UFG e Sociedade Midiática em Goiás - CNPQ. Autora do Livro: Célebre Sociedade.

${ }^{2}$ Professora Efetiva do Programa de Pós-Graduação da Faculdade de Comunicação e Biblioteconomia - FACOMB, da Universidade Federal de Goiás - UFG. Doutora em Comunicação pela Universidade Federal do Rio de Janeiro - UFRJ. Líder dos Grupos de Pesquisa Bases Epistemológicas para uma leitura crítica da mídia; Mídia, Imagem e Cidadania da UFG e Sociedade Midiática em Goiás - CNPQ. Autora dos livros: Deslumbramento Coletivo: Opinião Pública, Mídia e Universidade e Célebre Sociedade.
} 


\section{Introdução}

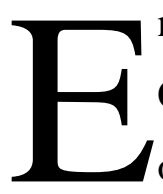

nfocar e ponderar a vida e obra do mais conhecido teórico lusófono das Ciências da Comunicação, José Marques de Melo, torna-se extremamente relevante quando adotamos o critério de que para que o conhecimento produzido seja válido, o empirismo precisa caminhar junto à teoria. Buscar o que acontece na realidade e no movimento das sociedades, através de análises e comparativos sociais relevantes, buscando comprovação ou mesmo produção teórica, ou seja, produzir e compartilhar é o que ensina José Marques de Melo.

Marques de Melo, pesquisador e pensador comunicacional da contemporaneidade, de enorme destaque na América Latina, começou sua atuação no espaço comunicacional antes mesmo de seu ingresso no curso de Comunicação Social - Habilitação em Jornalismo, da Universidade Católica de Pernambuco (UNICAP). Sua experiência e contato com a imprensa teve início em sua atuação nos jornais, "Gazeta de Alagoas", "Jornal de Alagoas", "Jornal do Comércio" e o "Última Hora”. Já enquanto acadêmico, seu interesse pela pesquisa em comunicação foi impulsionado por seu mestre, Luiz Beltrão.

Como parte do início precoce como profissional de comunicação, deu-se sua contratação pela Escola de Comunicações Culturais, primeira designação da ECA, na Universidade de São Paulo, neste momento José Marques de Melo possuía apenas 23 anos.

A atuação de José Marques de Melo, por meio de suas pesquisas, estudos, contribuições à Comunicação e à formação profissional de comunicólogos, agrega notoriedade à área, o que explica ser o pioneiro a perfilhar a existência de uma escola comunicacional latino-americana. Esta fundada a partir da leitura global do seu livro "Teoria da Comunicação: Paradigmas Latino-Americanos".

Assim, contribuiu Sousa em seu artigo "Revisitando o pensamento jornalístico de José Marques de Melo", p. 1738, publicado pelo $8^{\circ}$ Congresso LUSOCOM:

A acção de Marques de Melo é relevante para todo o universo das Ciências da Comunicação, até porque foi ele o primeiro autor a reconhecer a existência de uma escola de pensamento comunicacional latino-americana, fundada, conforme se deduz da leitura global do seu livro Teoria da Comunicação: Paradigmas Latino-Americanos, de 1998, na ideia de que a comunicação pode ser uma via para o desenvolvimento e para a educação, no cruzamento entre marxismo e cristianismo, no diálogo tenso entre capitalismo e socialismo como vias diferenciadas para o desenvolvimento, no engajamento ideológico e mesmo político dos seus mentores e ainda no hibridismo metodológico.

Comun \& Inf, v. 16, n. 1, p. 98-112, jan./jun. 2013 
Marques de Melo acredita que as pesquisas em comunicação, em contribuição com a produção midiática, devem proporcionar o vínculo permanente entre conteúdos e demandas ou preferências populares. Sobre pesquisas latino-americanas, contextualiza Melo (2004, p.33):

\begin{abstract}
A grande dificuldade latino-americana para estabelecer sintonia entre a agenda construída pelos produtores midiáticos e as expectativas das correntes majoritárias dos consumidores culturais está na ausência de pesquisa sistemática que ilumine as motivações da audiência. Como as empresas privadas que realizam ratings periódicos se limitam a mensurar os hábitos de consumo, caberia aos centros de pesquisa das universidades desvendar essa "caixa preta", evitando que se transfiram mecanicamente para nossas sociedades as concepções teóricas importadas das sociedades do norte, como se elas fossem aplicáveis às nossas realidades.
\end{abstract}

Os estudiosos latino-americanos lêem e analisam os estudos norte-americanos a partir de uma perspectiva crítica, centrando-se, muitas vezes, nas mediações midiáticas. Melo (2004) enfatiza a contribuição dos estudos culturais latino-americanos de Jesús Martín Barbero para a comunicação. Barbero entende a cultura popular, a cultura local como espaços de mediação, de apropriação, reinterpretação e fragmentação da cultura global pela mídia. Em contextos locais, de acordo com Barbero, a mídia atua em uma reconstrução simbólica.

\title{
1 Marques de Melo e o terreno da realidade para o avanço da pesquisa
}

$\mathrm{Na}$ atualidade, com o advento de uma indústria midiática produtora e disseminadora de ideologias, as considerações e os conceitos lógicos passam a se relativizar. Neste contexto, ícones, signos e personalidades ganham destaque nas sociedades. A ética da liberdade capitalista passa a permear a comunicação social e o próprio jornalismo, estes se tornam estetizados, mercantilizados e imagéticos.

Sobre esta estetização esclareceram Melo, Peruzzo e Kunsch (2003, p. 31):

A matriz do processo de mutação dos paradigmas do jornalismo é uma espécie de ideologia publicitária-mercadológica-liberal pós-moderna. A linguagem jornalística incorpora antes, durante, depois, sob, sobre, intra, inter e trans, a palavra, a linguagem e o discurso da racionalidade econômica da sociedade. Não só da razão pura do mercado, mas da estética, do simulacro e do teatro do mercado representados na mercadoria.

Em relação à mídia transformada em universal teatro virtual e a vida midiatizada e artificializada, Melo, Peruzzo e Kunsch (2003, p. 31) ainda corroboraram:

Na sociedade contemporânea, a informação, a notícia, o jornal e a imprensa em geral são estetizados, marquetizados e mercadorizados. A realidade dá lugar à estética da realidade. 
O esforço de objetividade dá lugar à estética da subjetividade. A apresentação torna-se uma representação protética e artificial.

Valioso ressaltar que foram os autores da Escola Latino-Americana os primeiros a advertirem sobre a problemática proeminente da globalização, internacionalização da informação e liberdade capitalista, bem como das consequências geradas por estes fatores nos países envolvidos.

Marques de Melo explica a relação gerada entre capitalismo, elite e meios de comunicação. Para o autor, a possibilidade de acesso aos veículos de comunicação está diretamente ligada à capacidade de aquisição e consumo do público. Quando este acesso torna-se difícil a determinada população, meios informais para propagação de informação são criados, trata-se da chamada folkcomunicação, de Luiz Beltrão. Sobre isso contextualiza Melo (1979, p. 9):

\begin{abstract}
Evidentemente, o acesso direto aos meios de comunicação está relacionado com o fenômeno da capacidade aquisitiva ou da distribuição do produto social, pois a compra de exemplares de jornais e revistas, de um ingresso de cinema ou a posse de aparelhos receptores de rádio e $\mathrm{TV}$, implica num dispêndio financeiro que nem sempre está ao alcance de todos os cidadãos. Mas, indiretamente, toda a sociedade está ao alcance dos meios de comunicação, porque o processo de transmissão das mensagens que veiculam obedece a um fluxo em dois estágios. No segundo estágio, a difusão se faz através dos meios informais de comunicação (folk-comunicação), assegurando uma penetração massiva em toda a comunidade que está no raio de audiência do instrumento formal de comunicação.
\end{abstract}

Historicamente, os meios de comunicação, especialmente no Brasil, ficaram marcados por uma conjuntura elitista em seus primórdios. Tal caráter de dominação pela elite é comprovado pelo período de censura da imprensa, em que todos os veículos informacionais e comuncacionais ficaram no domínio e controle das elites governamentais, deste modo conseguiam que a grande parcela da sociedade, desinformada, não tivesse contato com os ideais revolucionários.

Ao vigorar o liberalismo e com o advento da Revolução Industrial a comunicação, bem como a imprensa brasileira passam a assumir características direcionadas às massas, os produtos culturais adquirem maior circulação no Brasil. As informações passam a ser repassadas a um número mais expressivo de pessoas, por meio, principalmente, da televisão e do rádio. Marques de Melo em: "Comunicação, Opinião, Desenvolvimento" explica esta mudança de panorama no país.

O autor também expõe sobre o problema do não aumento na tiragem de jornais editados, fato constatado em vários períodos da história da imprensa na maioria dos países da América Latina, em relação ao crescimento populacional destes. O cenário justifica-se pelo caráter elitista da linguagem utilizada, limitando o acesso de receptores. $\mathrm{Na}$ atualidade, possível observar que a 
solução encontrada refere-se à segmentação de públicos, meios de comunicação específicos, destinados a públicos também específicos.

O intuito dos estudiosos latino-americanos da comunicação trata-se em propor um novo pensamento sobre as ações, práticas e atuações dos veículos massivos em relação à formação política, social e cultural dos cidadãos. A partir das reflexões geradas torna-se necessário que respostas e conjeturas práticas às sociedades latino-americanas sejam produzidas.

A respeito da escola latino-america explicou Temer e Nery (2009, p. 171):

A proposta da Escola Latino-Americana é gerar condições para repensar as práticas da comunicação e o papel que os meios massivos podem e devem desempenhas na formação da consciência política dos cidadãos. Nesta perspectiva, cabe aos professores, comunicadores e pesquisadores de comunicação conhecer em profundidade os processos de comunicação já desenvolvidos em outras escolas para, a partir deste conhecimento, conseguir elaborar alternativas radicais e realizáveis.

Contribuindo enormemente à construção do pensamento latino-americano de comunicação, José Marques de Melo, em seus estudos, trabalha a sistematização e organização teórica e de processos metodológicos para a geração de pesquisa. Os resultados alcançados e o conhecimento produzido são transferidos ao ensino e extensão, desta maneira fatores gerados por pesquisas passam a chegar e influir nas inter-relações dos processos comunicacionais das sociedades.

Uma de suas pesquisas, descrita na obra "Para uma Leitura Crítica da Comunicação", de 1985, versa sobre os programas televisivos locais, programas que circundam na área principal de atuação da emissora analisada.

Atestou que os programas destinados a entreter e divertir os telespectadores correspondiam a quase metade de toda programação. Os informativos, ao contrário, tinham percentual menor. Com índices mínimos, apareceram os especiais e os educativos.

Os gêneros de maior participação, em termos quantitativos, são os telejornais, os de variedades, as entrevistas e os esportivos. Quanto ao entretenimento, tem relevância percentual os shows de música e os programas de auditório. Já nos educativos, predominância de cursos.

Os especiais, que se caracterizam por apresentarem programas destinados a públicos específicos, apresentam com destaque os infantis e os religiosos. Quanto aos horários, verificou-se que os programas locais predominam no período vespertino.

Para serem apresentados, estes programas são subsidiados por incentivos e patrocínios. O maior percentual, como apresentado pela pesquisa, é de patrocinadores locais. Na Região Centro- 
Oeste, percebe-se boa participação de patrocinadores nacionais, enquanto no Leste e no Sul, há presença de patrocinadores estrangeiros. Assim, confirmou Melo (1985, p. 96)

\begin{abstract}
A identificação das relações de poder em qualquer sistema de comunicação significa elemento fundamental para se avaliar a conexão dos interesses políticos e econômicos que estão por detrás de suas mensagens, programas e campanhas. Não basta saber quem controla um determinado veículo, mas torna-se importante desvendar a teia de compromissos dos seus proprietários, pois assim é possível analisar com maior precisão o seu comportamento comunicativo.
\end{abstract}

Na pesquisa, Marques de Melo salienta, de maneira relevante, que mais da metade das concessões de canais haviam sido concedidas após 1964, ou seja, obedeceram às estratégias de segurança nacional e a princípios do regime militar. Grupos oposicionistas foram extirpados desse meio comunicacional e, na data da pesquisa, Melo ainda destaca que nenhum dos canais encontrava-se sob a posse de oposicionistas do governo ou de pessoas vinculadas a eles.

Em suas pesquisas, José Marques de Melo segue a linha de produção de conhecimento a partir do empirismo, foi o que demonstrou em "Para uma Leitura Crítica da Comunicação", "De Belém a Bagé: Imagens Midiáticas do Natal Brasileiro" e em "Identidade da Imprensa Brasileira no Final de Século: Das Estratégias Comunicacionais aos Enraizamentos e às Ancoragens Culturais". Por meio de sua procura e investigação pelo o que produz a realidade, no fervor e dinamismo das sociedades, Melo produz teoria, contribuindo ao pensamento comunicacional.

\title{
2 O Empirismo na obra de Melo
}

Marques de Melo assinala sua defesa referente à utilização de métodos empíricos para o conhecimento dos fenômenos comunicacionais. Seu rechaço a uma reprodução teórica sobre reprodução teórica é nítido, ele valoriza a utilização de elementos reais, que permeiam às sociedades, para a averiguação teórica e construção de conhecimento, ou seja, José Marques explora o empirismo a favor da ciência da comunicação.

Influenciado por autores como Horace Newcomb, Jacques Kayser, Luiz Beltrão e outros, Melo, através de seus estudos, vai apontar que descer ao plano prático e constatar empiricamente como são constituídas as ações reais trata de ser essencial nas pesquisas sociais e comunicacionais. Desta maneira o pesquisador tem a oportunidade de verificar e validar cientificamente as afirmações.

Marques de Melo (2004, p. 44) utiliza NEWCOMB (2000, p. 16) para relatar sobre o empirismo: 
Por sua vez, NEWCOMB prefere distanciar-se daquilo que ele chama de "guerras teóricas", recorrendo a uma angulagem nitidamente empírica. Ele postula a interação entre a pesquisa acadêmica e as demandas do sistema midiático. "nós precisamos reconhecer inicialmente a existência de problemas definidos, não por nós, através das complicadas fendas abertas pelos nossos pressupostos ou metodologias, mas efetivamente pelas circunstâncias que configuram os objetos reais do nosso estudo.

Refletindo a dialética da comunicação massiva com a comunicação popular, Melo empiricamente produz sua tese de doutorado. Nesta, as incógnitas consideradas reforçavam a idéia de que a ausência de urbanismo e consequentemente de cidadania inibiram o desenvolvimento da mídia impressa.

E, referente ao seu pós-doutorado e a valorização ao empirismo, o autor, no artigo "A utopia brasileira da mídia cidadã”, p. 26, publicado pela Revista Comunicação e Educação, ano XII completa:

Problematizei, no livro que reúne ensaios do pós-doutorado, o papel modernizador da mídia em sociedades que mantêm contingentes humanos à margem do desenvolvimento econômico. Anula-se completamente o estímulo à participação que a engrenagem midiática provoca nas audiências, tendo em vista a ausência do pleno exercício da cidadania.

Na obra "Estudos de Jornalismo Comparado", de 1972, Melo defende a utilização de métodos mais facilmente atinentes ao empirismo, uso que ele denomina de conotações aparentes, como melhor método para comparar os diferentes meios jornalísticos.

Neste estudo, coloca as matérias jornalísticas como unidades de análise de conteúdo, como faziam os autores que o antecederam quando promoviam abordagens científicas, todavia, as adapta à realidade brasileira, e a partir de então, cria métodos próprios para explicitar os detalhes e diferentes vertentes dos meios jornalísticos brasileiro.

Os resultados deste livro o levaram a realizar posteriores pesquisas. Nelas, tratou de transmitir a seus colaboradores das pesquisas setoriais a necessidade de que a interpretação dos dados e fenômenos de uma investigação científica devem sim ser embasados sob um prisma teórico, mas não pode ser esquecida a inclusão de dados empíricos.

Outro trabalho desenvolvido por Melo foi relativo à questão da linguagem das massas, tema abordado na obra “Comunicação, Opinião, Desenvolvimento”, de 1979.

Afirma o autor, em sua análise, que o comunicador, ao elaborar seu discurso, deve expressar as experiências culturais do receptor, assim como deve ter uma linguagem em sintonia com este. Nesse contexto, ainda cita a questão dos jornais brasileiros, que utilizam uma linguagem elitista e inviabiliza a leitura de públicos menos intelectualizados. 
No mesmo livro, analisa a influência dos meios de comunicação de massas. Afirma o autor que, tida como opinião da maioria, a opinião pública tem caráter dinâmico, proveniente das interações sociais.

Para maior entendimento e proeminência das questões empíricas para o universo da comunicação, valioso ressaltar uma entrevista de Marques de Melo ao blog Filosomidia, onde justifica o tema do Intercom 2011, "Quem tem medo da pesquisa empírica?”:

A pesquisa em comunicação emerge, no panorama das ciências humanas, no ramo dos estudos empíricos, situando-se como área do conhecimento aplicado. Sua natureza fenomenológica, servindo como fonte de referência para a tomada de decisões estratégicas, na retórica de Aristóteles ou na nova retórica de Schramm, não deixa dúvidas quanto à identidade adquirida na árvore mundial do saber. Trata-se de acervo cognitivo acumulado seletivamente pela práxis, legitimado historicamente pelas corporações de artes e ofícios, e democraticamente transmitido às novas gerações, através da oralidade, típica da era artesanal. Tornou-se artefato impresso, na idade industrial, abrigando a teoria sistematizada pelos mestres dos ofícios respectivos. Socializado através de manuais destinados ao aprendizado dos novos profissionais, o saber comunicacional manteve-se circunscrito ao empirismo hegemônico no período que antecede sua apropriação pela universidade.

Tuzzo e Braga Corroboram:

Toda comunicação entre as pessoas é fruto e reação dessas mesmas pessoas. A ciência desenvolvida nas Instituições de Ensino Superior não pode desconsiderar o que acontece fora dos limites das Universidades. Tudo é comunicação, ao passo que quase nada na sociedade se desenvolve sem ela. Os acontecimentos sociais devem ser observados e analisados cientificamente para que justifiquem a existência de uma teoria. A prática estudada e analisada não é menos teórica do que as teorias divulgadas em livros e congressos científicos. Comunicação é uma eterna relação entre sujeitos, atores, produtores e consumidores de um mesmo processo que deve ser sempre analisado em todas as suas esferas (TUZZO E BRAGA, 2011).

O empirismo trata de ser caracterizado como uma sabedoria conquistada a partir de percepções e visões de mundo. Trabalhando o esclarecimento, ideais conceituais de métodos e descobertas na Ciência da Comunicação, José Marques de Melo se consagrou como pesquisador e pensador da área. Ocupando posição memorável, atualmente, Melo é membro do Conselho Curador da Sociedade Brasileira de Estudos Interdisciplinares da Comunicação (INTERCOM).

\section{José Marques de Melo e o Jornalismo}

O trabalho de Marques de Melo realça sua devoção e advocacia do Jornalismo como campo científico independente e autônomo, o mantendo e sempre o considerando como atividade técnica e profissional, no seu horizonte de pesquisa, seja no cientificismo ou no empirismo. $\mathrm{O}$ autor considera que os órgãos jornalísticos não deveriam se prestar a serem apenas fontes de estudos jornalísticos, 
mas fontes de pesquisas para outras áreas e disciplinas, como história, ciências políticas, antropologia, dentre várias outras.

Nesse sentido, dá destaque a obras de autores que, ao longo do tempo, mostraram como o jornalismo pode ser uma prodigiosa fonte de pesquisa. Na história, por exemplo, cita Gilberto Freyre e Amaro Quintas, que promoveram o conhecimento do passado em relativização com o presente, através de textos publicados em jornais; além de citar, também, Alfredo de Carvalho, historiador do jornalismo.

Por parte de Melo, outro ponto que merece ressalva é a antiga discussão a respeito da objetividade jornalística. Ele compreende que se trata de um desafio profissional, ético e técnico dentro do jornalismo. O autor defende o ideal de que uma maior participação do profissional da comunicação na construção noticiosa pode distorcer a informação, ou seja, a opinião do jornalista passa a ser uma verdade ao público, e quando este recebe apenas a opinião de uma fonte jornalística, é evidente o risco em se assimilar aquela única opinião como verdade absoluta. Portanto, a capacidade e competência de noticiar implicam em uma habilidade técnica, metodológica e instrumental do jornalista.

Todo cidadão possui o direito de ser informado e o jornalista o direito à expressão de sua opinião no veículo de comunicação em que trabalha. Neste sentido, Marques de Melo entende que o direito do jornalista só pode ser praticado objetivando o cumprimento do direito democrático do cidadão em ter acesso à informação. Para Melo, este acesso pressupõe a necessidade de exposição, ao público, de variadas fontes sobre um mesmo assunto ou fato noticiado, antes da demonstração de opinião, interpretação e análise dos fatos, por parte do profissional de jornalismo ou do empresário de comunicação. Para Melo, desta forma, o cidadão terá a capacidade e a oportunidade de relacionar diferentes opiniões, bem como estabelecer considerações próprias, checar e correlacionar informações.

Melo afirma que a pesquisa brasileira em jornalismo se divide entre aquela que é realizada em função do objeto e a que considera o jornalismo como núcleo e analisa características do objeto. Em suas obras, enfatiza a última. Em um período em que as pesquisas em comunicação, e mais especificamente no jornalismo, situavam-se predominantemente sobre as teorias, Marques de Melo enveredou-se pelas pesquisas empíricas.

Um dos eixos centrais da obra de Marques de Melo circunda a recuperação e a valorização do pensamento autóctone brasileiro. Na obra "Teoria do Jornalismo: Identidades Brasileiras", de 2006, ele busca ideias de pensadores brasileiros que, ao longo dos anos, refletiram acerca do 
jornalismo. Inclui nestes Luiz Beltrão, seu primeiro mentor intelectual, além do professor português Nelson Traquina, que inseriu ideias no pensamento jornalístico brasileiro. Porém, para Melo, a contribuição exógena ao jornalismo não considerou as condições históricas e sócio-culturais do Brasil.

Em "Para uma leitura crítica da comunicação", José Marques traça o panorama da história da imprensa no Brasil, ressaltando todos os entraves para sua implantação tardia. De acordo como o Melo (1985, p. 117):

O Brasil foi um dos últimos países das Américas a contar com o funcionamento da imprensa. Três séculos depois da instalação da tipografia na América espanhola e dois séculos após o surgimento na América inglesa é que o Brasil ingressaria no período histórico que mais tarde Marshall Mcluhan chamou "Galáxia de Gutenberg".

Dentre os motivos que levaram ao demorado desenvolvimento da imprensa brasileira estava a dificuldade para a emancipação política do país de Portugal, bem como uma diversidade de elementos sócio-culturais aliados à ausência de urbanização, analfabetismo, inexistência de atividades industriais e comerciais.

Melo lembra algumas tentativas, ainda no período colonial, de implementação desta imprensa, nenhuma delas alcançou êxito. Entre elas a primeira ocorreu em Recife no ano de 1642, época de dominação holandesa, neste momento aquela sociedade já contava com algum incremento urbano, Nassau, então, se esforçou para conseguir uma tipografia, mas análises históricas provam que tal aquisição não ocorreu neste período.

A segunda tentativa alcançou sucesso por vinte anos no Paraná, contudo por desvincular-se de sua conjuntura local não prosperou. Esta imprensa possuía a finalidade de evangelizar os índios, através da utilização das línguas nativas. Entretanto, a tipografia, ali, fracassou quando se buscou a propagação da língua espanhola.

Ligadas às vontades elitistas, as tipografias de Recife e Rio de Janeiro não repercutiram, tão menos a que surgiu no estado da Bahia com o objetivo de produzir cartas para jogo. Como é possível ser observado, são as questões sociais e estruturais brasileiras, explanadas por Melo, responsáveis por retardar a instalação da imprensa no país.

Quando o Brasil sedia o reinado de Portugal, no Rio de Janeiro, duas tipografias passam a funcionar. Uma oficina aberta por patrocínio de Conde dos Arcos, na Bahia e a Imprensa Régia, no Rio de Janeiro. Observa-se que mesmo após a proclamação da independência, a ampliação e expansão da imprensa pelo território nacional acontecem de maneira vagarosa e pausada, durante 
trinta anos. Este quadro é explicado pela ainda existência de elementos sociais e culturais que limitam a sobrevivência e sucesso de jornais e tipografias no Brasil.

Surgindo como meio de disputas políticas, a imprensa, mesmo que artesanal, vai adquirindo relevância nas sociedades. Foi o que Marques de Melo (1985, p. 122-123) explicita:

Tecnicamente, trata-se de uma imprensa artesanal. Estruturalmente, caracteriza-se por ser episódica. Proliferam os pasquins e se sucedem os jornais de opinião. São veículos criados e mantidos em função de movimentos políticos, oscilando de acordo com as flutuações dos seus proprietários no controle de aparelho burocrático do Estado. Em síntese, são jornais sem lastro duradouro, que recorrem até mesmo à captação de anúncios, sem deles depender exclusivamente, e que buscam subsídios governamentais, mas cujo objetivo maior é a participação política, a intervenção decidida na luta pelo poder.

Uma nova perspectiva à sociedade brasileira surge com a libertação dos escravos e a instauração do regime republicano. Reflete, a partir daí, uma mudança no caráter elitista da imprensa, esta passa a ser utilizada, também, como canal de comunicação das classes de trabalhadores. Sindicatos e associações do operariado passam a usar a imprensa com o objetivo de expressarem e propagarem seus interesses. Neste contexto surgem as empresas jornalísticas pioneiras no Brasil, junto a um aprimoramento do sistema capitalista no país. Estas organizações, portanto, passam a se manter a partir do lucro gerado pela venda de publicidade, bem como pelos subsídios estatais.

A imprensa no Brasil segue mostrando-se em dependência em relação ao Estado que "ocorre desde a libertação das cotas de papel (eventualmente subsidiadas) até a obtenção de empréstimos dos bancos oficiais (ou de aval para transações com bancos estrangeiros), passando pelo escalonamento (ou perdão) das dívidas previdenciárias, pelas isenções fiscais, pela tolerância nas fiscalizações trabalhistas etc. etc.” (MELO, 1985, p. 125).

Além da dependência estatal, a imprensa brasileira passa a se subordinar ao capital do exterior, o maior anunciante. Melo pontua detalhadamente este quadro de subordinação. Empresas de comunicação que ousaram ser independentes chegaram ao fracasso, sofreram repressões. Foi o que aconteceu com o "Correio da Manhã”, “Jornal da República”, entre outros.

Tal patamar evidencia crise na imprensa, mesmo em períodos de avanços tecnológicos. Os motivos para infeliz circunstância são detectados por Marques de Melo (1985, p.126):

a) O número de jornais tem diminuído. Grandes jornais estão morrendo ou sendo incorporados por outros, sem o nascimento de novos. Pequenos jornais, em geral oposicionistas, e por isso rotulados como "imprensa alternativa", nascem, mas não conseguem sobreviver. b) O número de leitores não cresce, o que significa a redução global das tiragens. Segundo estatísticas da UNESCO, a imprensa brasileira registrou, na década 
de 60, uma queda da ordem de 500 mil exemplares. Isso é paradoxal, se tivermos em conta o aumento populacional, a expansão da rede educativa e a melhoria da capacidade aquisitiva daqueles setores da classe média que se beneficiaram com o "milagre econômico".

Um maior acesso à informação, por parte da população, através de uma sonhada imprensa democrática, que conseguisse se expandir e levar ciência factual ao grande público sofre grandes entraves decorrentes de alguns fatores, pontuados por José Marques de Melo: "incapacidade aquisitiva do povo brasileiro", "analfabetismo crônico", "ausência de participação política" e "elitismo da imprensa".

Entende-se que somente através de mudanças nos cenários políticos e econômicos do país uma democratização da imprensa brasileira seria possível. Através de um maior acesso social à informação, uma opinião pública verdadeira, de fato, talvez pudesse ganhar força. É como afirmou Melo (1979, p. 43), “O processo de formação da Opinião Pública envolve todo um complexo de circulação das informações na comunidade.” Ou seja, a democratização da comunicação precede a construção da opinião pública no Brasil.

\section{Considerações Finais}

José Marques de Melo é um dos mais proeminentes teóricos lusófonos da Língua Portuguesa e analisar e contextualizar sua vida e obra torna-se de extrema relevância, partindo do pressuposto de que, embora o autor enfatize o empirismo, este precisa estar aliado à teoria para tornar-se válido.

Melo incentiva e ensina a buscar através de dados e elementos informacionais, o que ocorre nas sociedades e nas consequências de suas movimentações, comprovando-os ou utilizando bases teóricas para elucidar o real.

Pesquisador contemporâneo, o autor sempre buscou a realidade em suas pesquisas, e por isso, o empirismo foi o modelo adotado para este fim. Melo enfatiza o grande público e considera o conhecimento empírico como algo que completa a ciência, baseado nas experiências. Entretanto, como defensor desse método, sempre avaliou que não existe empirismo sem base teórica, e não há base teórica sem conhecimento científico, ou seja, seu objeto caminhava lado a lado com o conhecimento científico, embora o foco fosse o empirismo.

Tratou de analisar o terreno da realidade de maneira verossímil, explicitando as verdadeiras nuances da mídia, como seu papel, seu poder, sua influência, tudo a partir de dados e elementos colhidos através de pesquisas que exaltavam os elementos sociais e culturais. Suas obras, ao contrário do que acontecia no período em que iniciou suas publicações, não registravam elementos

Comun \& Inf, v. 16, n. 1, p. 98-112, jan./jun. 2013 
de teoria sobre elementos de teoria, mas, através destas, colhiam na sociedade e nos membros as reais características dos fatos e das diversas perspectivas midiáticas.

Artigo submetido em 01/07/2013 e aceito em 24/07/2013.

\section{Referências}

MELO, José Marques de. A esfinge midiática. São Paulo: Paulus, 2004.

MELO, José Marques de. Comunicação e modernidade. São Paulo: Editora Loyola, 1991.

MELO, José Marques de. Comunicação, opinião, desenvolvimento. Petrópolis: Vozes, 1979.

MELO, José Marques de. Comunicação: teoria e política. São Paulo: Summus, 1985.

MELO, José Marques de. Estudos de jornalismo comparado. São Paulo: Pioneira Editora, 1972.

MELO, José Marques de. Para uma leitura crítica da comunicação. São Paulo: Edições Paulinas, 1985.

MELO, José Marques de. Teoria da comunicação: paradigmas Latino-Americanos. Petrópolis: Vozes, 1998.

MELO, José Marques de. Jornalismo brasileiro. Porto Alegre: Sulina, 2003.

MELO, José Marques de. Teoria do jornalismo: identidades brasileiras. São Paulo: Paulus, 2006.

MELO, José Marques de; KUNSCH, Waldemar Luiz (Orgs.). De Belém a Bagé: imagens midiáticas do Natal brasileiro. São Bernardo do Campo: Cátedra UNESCO/UMESP, 1998.

MELO, José Marques de; PERUZZO, Cicilia M. Krohling; KUNSCH, Waldemar Luiz. (Org.).

Mídia, regionalismo e cultura. São Bernardo do Campo: Assahi Gráfica e Editora, 2003.

MELO, José Marques de; QUEIROZ, Adolpho. Identidade da imprensa brasileira no final de século. São Bernardo do Campo: Cátedra UNESCO/UMESP, 1998.

TEMER, Ana Carolina Rocha Pessoa; NERY, Vanda Cunha Albieri. Para entender as teorias da comunicação. Uberlândia: EDUFU, 2009.

SOUSA, Jorge Pedro. Revisitando o pensamento jornalístico de José Marques de Melo. Disponível em: <http://conferencias.ulusofona.pt/index.php/lusocom/8lusocom09/ paper/viewFile/65/43>. Acesso em: 16 jun. 2011.

MELO, José Marques de. Intercom 2011: quem tem medo da pesquisa empírica? Disponível em: <http://filosomidia.blogspot.com/2011/03/intercom-2011-quem-tem-medo-da-pesquisa.html>. Acesso em: 25 jul. 2011. 
.

MELO, José Marques de. A utopia brasileira da mídia cidadã. Disponível em:

<http://www.revistasusp.sibi.usp.br/pdf/ced/v12n1/v12n1a04.pdf>. Acesso em: 02 jul. 2011.

TUZZO, Simone Antoniaci; BRAGA, Claudomilson Fernandes. Quem tem medo de pesquisa empírica? In: CONGRESSO DE CIÊNCIAS DA COMUNICAÇÃO NA REGIÃO CENTROOESTE, 13., 2011, Mato Grosso. Anais... Mato Grosso: UFMT, 2011. 